\title{
Transpapillary Drainage of Persistent Pseudocyst Causing Dysphagia
}

\author{
Grace E Kim, MD ${ }^{1 *}$, David Y Lo, MD, FACG, FASGE, AGAF',3
}

${ }^{1}$ Department of Internal Medicine, University of Maryland Medical Center, Baltimore, USA

${ }^{2}$ Ohio Gastroenterology Group, Inc., Columbus, USA

${ }^{3}$ The Ohio State University College of Medicine, Columbus, USA

A 47-year-old female with history of chronic alcohol-related pancreatitis presented with dysphagia and mild weight loss. Esophagram demonstrated a stricture of the distal esophagusre sembling a bird's beak (Figure 1). Esophagogastroduodenoscopy showed a nonrelaxing distal esophagus, with balloon dilation unsuccessful in relieving her symptoms. Magnetic resonance imaging demonstrated a pancreatic duct stricture (Figure 2, arrow) with upstream $6 \mathrm{~cm} \times 5.3 \mathrm{~cm}$ pseudocyst (Figure 2, asterisk) compressing the distal esophagus. Endoscopic ultrasound did not reveal evidence of a pancreatic mass, and cystgastrostomy was attempted but not feasible due to the proximal location of the pseudocyst. Endoscopic retrograde cholangiopancreatography (ERCP) demonstrated a high-grade stricture at the genu with upstream pancreatic duct (PD) dilation and communication with the pseudocyst, thus transpapillary pseudocyst drainage with a double pigtail stent was performed while stenting the PD stricture (Figure $3)$. Stricture brushings were negative for malignancy. After se-

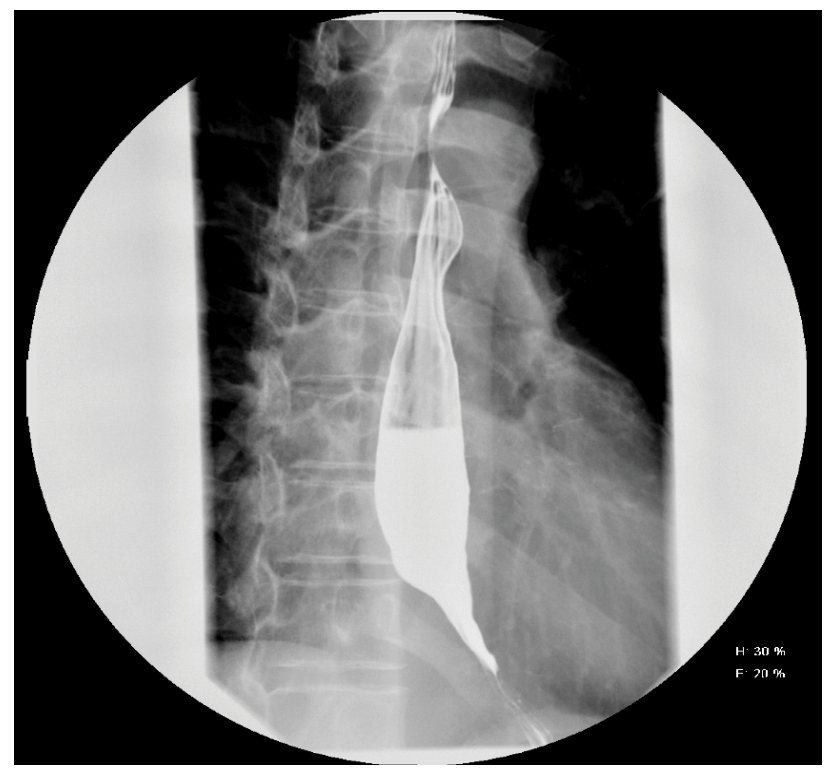

Figure 1: Esophagram showing bird's beak appearance. rial PD stenting during subsequent ERCPs, the patient's dysphagia, PD stricture, and pseudocyst resolved.

Dysphagia due to pseudocysts is rarely reported. This is usually due to mediastinal extension of a pseudocyst via the retroperitoneum. This case highlights that other differentials

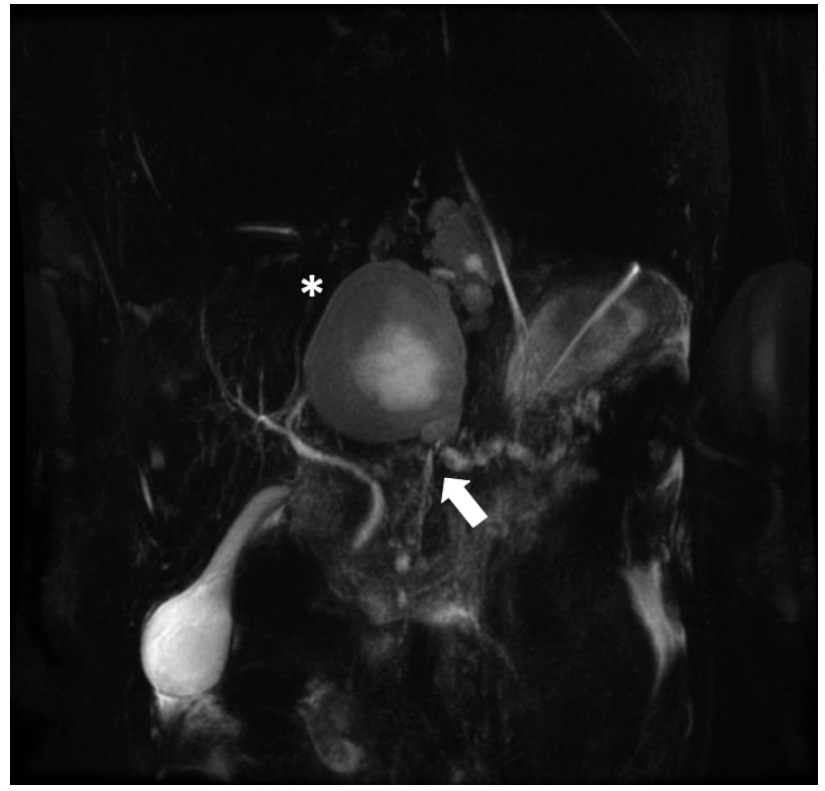

Figure 2: MRCP showing PD stricture (arrow) with upstream PD dilation, and pseudocyst (asterisk).

\footnotetext{
*Corresponding author: Grace E Kim, MD, Department of Internal Medicine, University of Maryland Medical Center, 22 South Greene St. Baltimore, MD 21010, USA, Tel: 240-750-0466

Accepted: September 26, 2020

Published online: September 28, 2020

Citation: Kim GE, Lo DY (2020) Transpapillary Drainage of Persistent Pseudocyst Causing Dysphagia. J Gastrointest Hepat Surg 3(1):37-38
} 


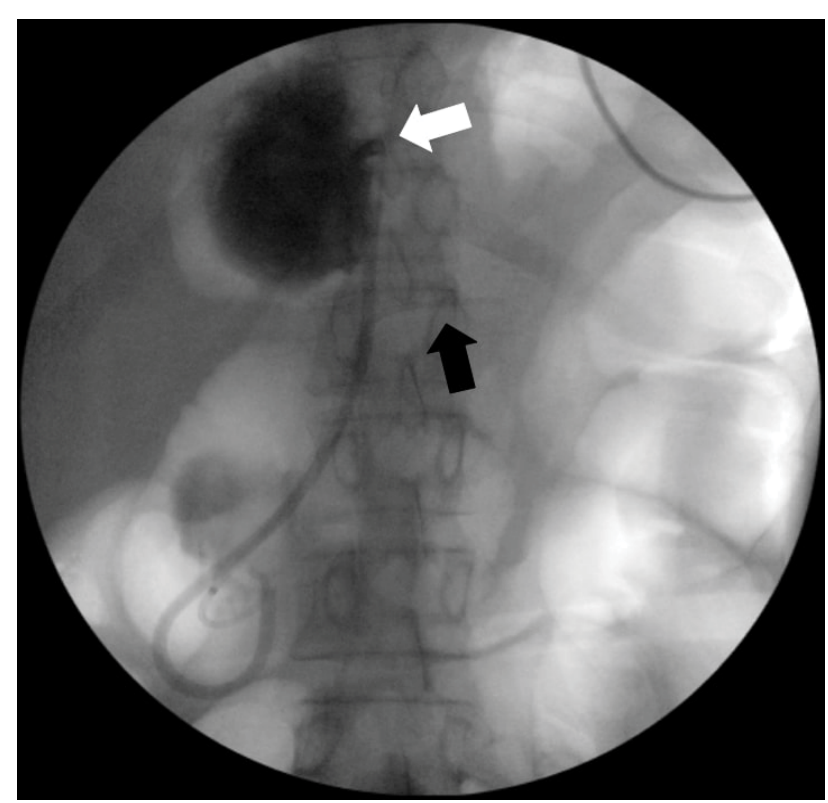

Figure 3: ERCP showing double pigtail stent draining pseudocyst (white arrow) and PD stent bridging the genu stricture (black arrow). in addition to achalasia should be considered when encountering bird's beak on esophagram in a patient with chronic pancreatitis.

\section{Conflict of Interest}

Dr. Grace Kim and Dr. David Lo do not report any relevant conflicts of interest.

DOI: $10.36959 / 879 / 379$ 